\title{
Resenba
}

\section{Saúde Coletiva e Urgência em Educação Física e Esportes}

\author{
[Aguinaldo Gonçalves (org.) e colaboradores]
}

\author{
Giovani De Lorenzi Pires*
}

A emergência de novas concepções na Educação Física brasileira, a partir da década de 80 , orientadas em pressupostos das ciências humanas e sociais, estabeleceu um significativo contraponto ao amplo predomínio do enfoque biologicista que, até então, havia se constituído na principal referência curricular dos cursos de graduação. A extinção da obrigatoriedade do currículo mínimo do Conselho Federal de Educação determinou revisões estruturais que atingiram as disciplinas da chamada base biomédica. Sem o "charme" da Fisiologia do Esforço, da Teoria do Treinamento Esportivo ou mesmo da Biomecânica, outras disciplinas como Higiene, Saúde Coletiva e Urgências em Educação Física/Esportes passaram a se constituir, desde então, nas "menores carentes" dos cursos de formação profissional. Colocadas em pontas inexpressivas das respectivas grades, ministradas por profissionais nem sempre comprometidos com o cotidiano da Educação Física, com escasso e pouco apropriado material didático e bibliográfico, esta ainda parece ser a realidade dessas disciplinas.

Conhecedores de tal problemática por estarem, muitos deles, diretamente envolvidos com docência em programas nessa área em Faculdades de Educação Física no Estado de São Paulo, Aguinaldo Gonçalves e seus colaboradores (1997) chamaram para si a responsabilidade de uma difícil tarefa: a partir de ações coletivas empreendidas para resolver seus próprios problemas com essas disciplinas, produziram textos que agora reelaborados e reunidos podem subsidiar a ação docente em Higiene e Urgência em Educação Física, na graduação e pós-graduação. De tal compromisso, resultou o livro Saúde Coletiva e Urgência em Educação Física e Esportes, que em boa hora é lançado pela Papirus.

Antes de comentar o livro, é importante fazer breve referência aos autores. Aguinaldo Gonçalves dispensa maiores apresentações, em vista do seu reconhecido trabalho acadêmicoinstitucional e em entidades científicas, como no Colégio Brasileiro de Ciências do Esporte. Entre seus colaboradores, mais do que nomes, cabe ressaltar a diversidade das suas áreas de formação e atuação, que empresta um caráter multidisciplinar à obra. Além de profissionais da Educação Física com pós-graduação na área e em Educação, participam da produção Doutor em Saúde Pública, Bibliotecária, Fisioterapeuta e Educadora em Saúde Pública.

É de se registrar, desde já, perspectiva colocada na sua apresentação, no sentido de que a obra possa constituir e ampliar processo cooperativo entre profissionais da área, de diferentes instituições, para a produção/aplicação/veiculação de conhecimentos e metodologias, integrados à rede de investigação (RI) em ensino. Essa estratégia já vem sendo implementada com sucesso em nível internacional e mesmo no Brasil, através de iniciativas coletivas de pesquisadores da área da saúde, com apoio de agências de fomento como o CNPq e a FAPESP. De fato, parece ser esta uma iniciativa que garantiria, entre outras vantagens, a otimização dos recursos humanos, materiais e financeiros já disponíveis ou a se- 
rem alocados, mediante projetos cooperativos entre pesquisadores e/ou laboratórios associados.

Na perspectiva de constituir um quadro de referência em Saúde Coletiva e Urgência em Educação Física e Esportes, os autores optam por tratar a área como um espaço interdisciplinar por excelência. Com profusão de dados nacionais e internacionais sobre Saúde Coletiva, estudos epidemiológicos sobre lesões e agravos relacionados à Educação Física e Esportes, além de sugestões de condutas em urgências, o livro oportuniza uma leitura, em sua maior parte, acessível, permitindo seu uso tanto como material de consulta para docentes e acadêmicos quanto na forma de textos didáticos, em vista da estrutura dos seus capítulos, todos autônomos, mas complementares.

Precedido por uma apresentação explicativa do autor-coordenador, o livro é composto por 13 capítulos, que constituem quatro partes: 1) saúde coletiva e epidemiologia, onde se descrevem as atuais bases conceituais da área; 2) saúde e urgência, em que se buscam aproximações com situações concretas no campo da Educação Física e Esportes, sugerindo condutas de socorrismo; 3) lesões esportivas, espaço para identificação de tipos recorrentes de lesões agudas e crônicas, apontando para modalidades esportivas e aspectos epidemiológicos da questão; 4) saúde coletiva e atividade fisica, relação controversa como afirmam os próprios autores, ocupa-se de demonstrar os determinantes históricos e disciplinares das produções na área.

O principal mérito da obra está na abordagem social dada aos problemas relativos à questão da saúde que, historicamente, têm sido enfocados pela Educação Física. Rejeitando a visão funcionalista, tão tradicional nos discursos da e para a nossa área, que transforma as relações de saúde-atividade física em um bem individual a ser buscado ou, mais do que isso, numa obrigação (auto)imposta ao cidadão, o livro de Gonçalves e colaboradores ressalta as responsabilidades individuais e os compromissos públicos que precisam ser observados para que não se caia na falsa dicotomia subjetivo $\mathrm{x}$ objetivo. A esse respeito, Carvalho (1996) observa que, em saúde coletiva, cada vez mais é necessário superar as decisões mutuamente excludentes entre o individual e o coletivo, entre o público e o particular, a fim de que sejam implementadas ações integradoras que, sobretudo, objetivem tanto o prolongamento da expectativa de vida humana como igualmente melhorar sua qualidade. Referindo-se à complexidade do processo da saúde coletiva, aquele autor ressalta que é necessário "abrir caminhos para novas abordagens terapêuticas voltadas não mais para o evitamento de fatores de risco isolados ou para o combate a seus efeitos, mas à promoção de situações mais favoráveis à saúde" (p.107).

Tal preocupação pode ser observada em diversos trechos da obra em apreciação, por vezes de forma menos evidente, em outros momentos mais explicitamente. É o que se encontra, por exemplo, no capítulo em que Corrêa Filho, Gonçalves e Gonçalves traçam panorama da realidade brasileira em termos de saúde coletiva, demonstrando que as chamadas patologias da modernidade (como as crô-nicodegenerativas e ocupacionais) ainda convivem com doenças resultantes de carências infraestruturais (como a subnutrição e as doenças diarréicas). Ainda nessa linha, Gonçalves, Gonçalves e Matiello Jr. trazem contribuições com base nos aspectos sociais, fazendo conexões importantes com as Ciências do Esporte, notadamente com relação às doenças hipocinéticas vinculadas ao estresse e ao sedentarismo, e à fadiga decorrente do modo de desenvolvimento econômico-social. Também vale citar o texto exploratório sobre a relação saúde coletiva/atividade física assinado por João Paulo Medina e Aguinaldo Gonçalves, apontando para o seu entendimento na perspectiva do "ser humano, situado em realidade coletiva e historicamente produzida" ( $p$. 151).

De fato, pode-se perceber no decorrer da leitura a opção pela abordagem social nos estudos sobre a questão da saúde coletiva. No quadro de referências do livro, estão citados vários autores que perseguem referida vertente. Todavia, em vista da sua peculiaridade frente aos demais entendimentos da relação saúde/atividade física presentes no âmbito da Educação Física, e também em face de outros fatores limitantes aos profissionais e gra-duandos da área, como dificuldades de acesso a tais bibliografias, seria de todo apreciável um tópico que, concentrada e introduto-riamente, além de explicitar claramente o pressuposto adotado, também o fundamentasse 
conceitualmente, situando-o no conjunto dos atuais estudos relacionados à saúde coletiva.

Mas essa, talvez, seja surpresa que o professor Aguinaldo e seus colaboradores estejam nos reservando para uma nova publicação. Podemos aguardar?

\section{REFERÊNCIAS BIBLIOGRÁFICAS}

CARVALHO, Antônio Ivo de. Da saúde coletiva às políticas saudáveis: saúde e cidadania na pósmodernidade. Ciência e Saúde Coletiva, v.l, n.1, p.104-21, 1996.

GONÇALVES, Aguinaldo (org.) e colaboradores. Saúde coletiva e urgência em Educação Física e Esportes. Campinas: Papirus, 1997.

*Professor do RPD/Centro de Desportos/UFSC, doutorando em Ciências do Esporte (FEF/ UNICAMP) e bolsista PICD/CAPES. 